\title{
Development and Content Validation of a Patient-Reported Sexual Risk Measure for Use in Primary Care
}

\author{
Rob J. Fredericksen, $P h D^{7}$, Kenneth H. Mayer, $M D^{2}$, Laura E. Gibbons, $P h D^{7}$, Todd C. Edwards, $P h D^{7}$, \\ Frances M. Yang, PhD ${ }^{3}$, Melonie Walcott, PhD ${ }^{4}$, Sharon Brown, MPH/MSW', Lydia Dant, MPH ${ }^{2}$, \\ Stephanie Loo, MSC ${ }^{2}$, Cristina Gutierrez, BA ${ }^{2}$, Edgar Paez, MSC ${ }^{5}$, Emma Fitzsimmons, BA ${ }^{7}$, \\ Albert W. Wu, MD', Michael J. Mugavero, MD ${ }^{4}$, William C. Mathews, MD ${ }^{5}$, William B. Lober, MD', \\ Mari M. Kitahata, $M D^{7}$, Donald L. Patrick, $P h D^{7}$, Paul K. Crane, MD', and Heidi M. Crane, $M D^{7}$
}

${ }^{1}$ Center for AIDS Research, University of Washington, Seattle, WA, USA; ${ }^{2}$ Fenway Community Health, Boston, MA, USA; ${ }^{3}$ Augusta University, Augusta, GA, USA; ${ }^{4}$ University of Alabama, Birmingham, AL, USA; ${ }^{4}$ University of California, San Diego, CA, USA; ${ }^{6}$ Johns Hopkins University, Baltimore, MD, USA.

BACKGROUND: Patient-provider sexual risk behavior discussions occur infrequently but may be facilitated by high-quality sexual risk screening tools.

OBJECTIVE: To develop the Sexual Risk Behavior Inventory (SRBI), a brief computer-administered patientreported measure.

DESIGN: Qualitative item development/quantitative instrument validation.

PARTICIPANTS: We developed SRBI items based on patient interviews $(n=128)$ at four geographically diverse US primary care clinics. Patients were diverse in gender identity, sex, sexual orientation, age, race/ethnicity, and HIV status. We compared sexual risk behavior identified by the SRBI and the Risk Assessment Battery (RAB) among patients $(n=422)$.

APPROACH: We constructed an item pool based on validated measures of sexual risk, developed an in-depth interview guide based on pool content, and used interviews to elicit new sexual risk concepts. We coded concepts, matched them to item pool content, and developed new content where needed. A provider team evaluated item clinical relevance. We conducted cognitive interviews to assess item comprehensibility. We administered the SRBI and the RAB to patients.

KEY RESULTS: Common, clinically relevant concepts in the SRBI included number of sex partners; partner HIV status; partner use of antiretroviral medication (ART)/ pre-exposure prophylaxis (PrEP); and recent sex without barrier protection, direction of anal sex, and concern regarding HIV/STI exposure. While 90\% reported inconsistent condom use on the RAB, same-day SRBI administration revealed that for over one third, all their partners were on ART/PrEP.

CONCLUSION: The SRBI is a brief, skip-patterned, clinically relevant measure that ascertains sexual risk behavior across sex, sexual orientation, gender identity, partner HIV serostatus, and partner treatment status, furnishing providers with context to determine gradations of risk for $\mathrm{HIV} / \mathrm{STI}$.

Received October 9, 2017

Revised February 21, 2018

Accepted May 11, 2018

Published online May 29, 2018
KEY WORDS: sexual risk behavior measurement; patient-reported outcomes.

J Gen Intern Med 33(10):1661-8

DOI: $10.1007 / \mathrm{s} 11606-018-4496-5$

(C) Society of General Internal Medicine 2018

\section{INTRODUCTION}

Despite rising rates of sexually transmitted infections (STI) in the USA, ${ }^{1}$ sexual risk behavior (SRB) is under-addressed in clinical care, ${ }^{2-5}$ including among higher-risk populations, such as men who have sex with men (MSM), ${ }^{6}$ and patients in HIV care ${ }^{4,7-10}$ including methamphetamine users. ${ }^{8}$ Reasons include time constraints, provider discomfort discussing the topic, and inaccurate risk perception. ${ }^{3-5,11-16}$

Computer-administered clinical assessments that include patient-reported SRB may decrease some of these barriers by identifying those with SRB and minimizing social desirability bias. ${ }^{17-20}$ Clinical assessments of patient-reported outcomes and measures (PROs) have been well-tolerated among patients and useful to providers. ${ }^{21-24}$ We have shown that delivering same-day clinical assessment PRO results to providers at the point of care can change provider awareness and/or actions for domains such as depression, substance use, and antiretroviral (ART) medication adherence. ${ }^{25}$ In that same study, we found that SRB assessment with a legacy scale, an adaptation of the Risk Assessment Battery (RAB), ${ }^{26,27}$ did not result in substantial changes in provider care. Further, informal patient and provider feedback suggested that the RAB was lengthy, disliked by patients, and did not yield clinically actionable information.

Measurement of patient-reported SRB lacks a gold standard. $^{20,28,29}$ SRB measures are difficult to validate ${ }^{30}$ and heterogeneous in response format, ${ }^{28,31}$ recall period, ${ }^{28}$ and content. ${ }^{28}$ Many are population- or project-specific, ${ }^{29,32}$ rendering them impractical for routine administration in general primary care. We thus aimed to develop an improved measure to elicit clinically actionable SRB for use in busy clinical care settings. 
We developed the Sexual Risk Behavior Inventory (SRBI), a touch-screen-administered measure for use in primary care with patients that is inclusive of diverse gender identities, sexual orientations, and of patient and partner HIV status, employing skip patterns to minimize patient burden. The SRBI identifies behaviors necessary to assess SRB in the absence of barrier protection, including serosorting, anal sex role among MSM, and partner use of ART/pre-exposure prophylaxis (PrEP) medications.

\section{METHODS}

\section{Methodological Overview}

Figure 1 provides a methodological overview. In concordance with NIH-Patient Reported Outcomes Measurement Information System (PROMIS) recommendations for instrument development, ${ }^{33}$ we developed a literature-review-based item pool of legacy SRB items. We categorized similar items, winnowing items within each to the best alternatives. We

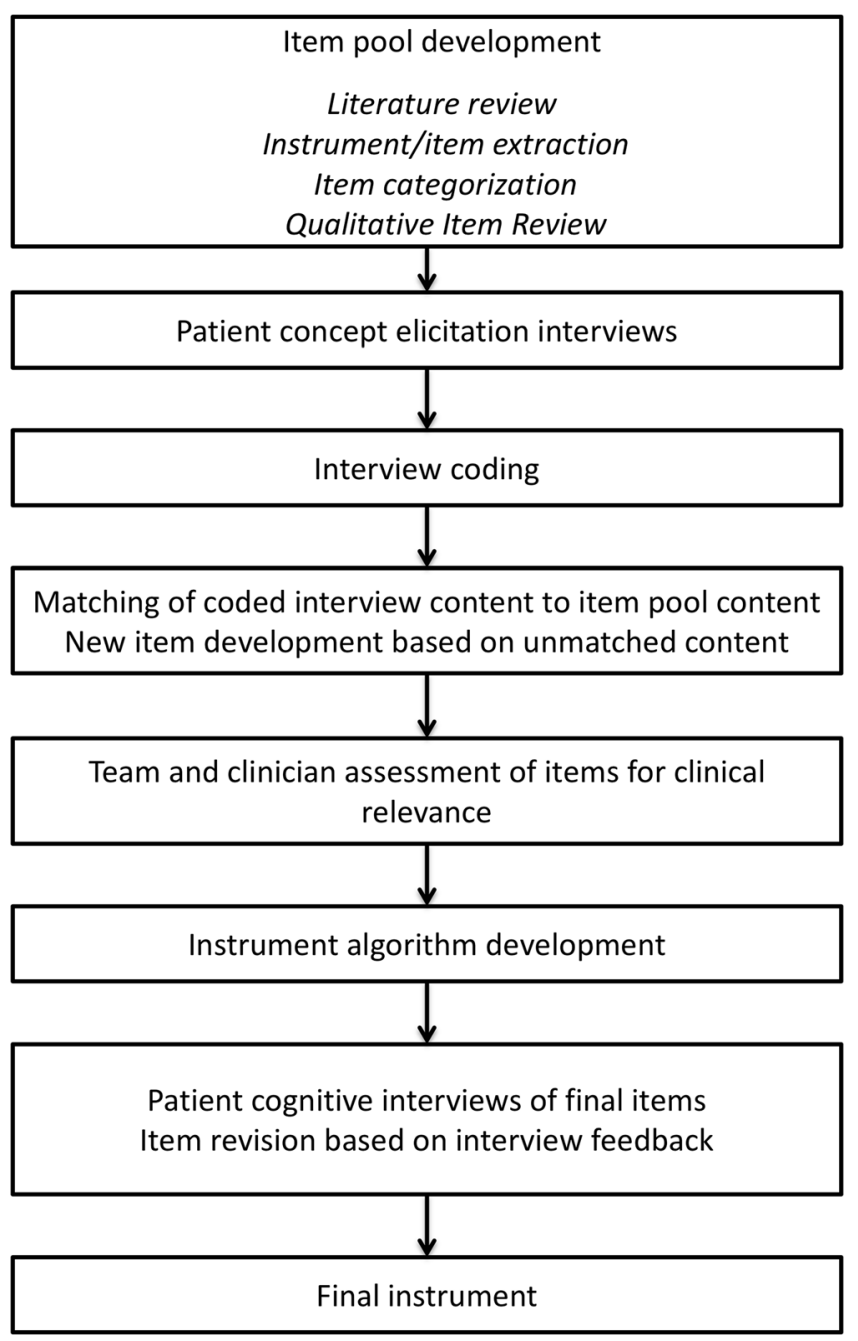

Fig. 1 Methodological overview. designed an in-depth interview guide covering content areas. We conducted concept elicitation (CE) interviews with patients, coded transcripts to match item pool content, and identified salient unmatched content requiring new item development. A panel of HIV care providers prioritized candidate items based on clinical relevance. We presented selected items to patients for cognitive interviewing, using their feedback to clarify item language when needed. We administered the resulting SRBI to patients alongside the legacy RAB. Human subject committees at each site approved all research activity.

\section{Item Pool Development}

We convened a team of clinicians and study investigators to establish a governing concept of SRB; we defined this as "engagement in behavior which exposes one to risk of STIs." We reviewed literature with the assistance of reference librarians using Medline to identify SRB measures developed or used in care since 2003. We included measures of SRB, sex addiction, condom attitudes, condom self-efficacy, and sensation seeking. Our initial search yielded 165 citations. We excluded instruments from population-based surveys not intended for clinical care, instruments not in North American English, instruments requiring interviewer administration, instruments with content outside our governing concept, older versions of since-updated instruments, and instruments unavailable after two attempts to contact authors. This strategy yielded 18 instruments and 273 items.

\section{Item Categorization}

Two qualitative researchers independently categorized candidate items using an open-coding process; from this process, the larger qualitative team met to achieve consensus on final fixed codes. We identified four general thematic areas for categorization: generic sexual behavior (e.g., without querying risk or preventive behavior), risk/prevention practices (e.g., condom use or lack thereof), reasons for loss of control (in a sexual situation), and sex in exchange for money/goods/assistance. We further coded items into subgroups termed "factors"; for example, the category of "risk/prevention practices" included items organized by factors of "barrier protection," "discussion with partner," and "avoiding fluid exchange."

Three reviewers with content area expertise independently winnowed items into a smaller pool, selecting the best among alternatives with similar content, using the PROMIS Qualitative Item Review (QIR) process. ${ }^{34}$ We reconciled discordance through group discussion, resulting in a pool of 85 distinct candidate items.

\section{Concept Elicitation Interviews}

We used content areas from these items to develop an interview guide that elicited concepts of patient SRB. We consulted content area experts to maximize relevance across sexual orientation and gender identity. 
We invited patients for hour-long interviews, offering $\$ 25$ compensation. We presented patients with items from the modified RAB that assessed frequency of condom use. ${ }^{35} \mathrm{We}$ invited patients to provide comment/critique on the items; this familiarized patients with typical domain content. We asked patients what they understood about HIV/STI transmission and prevention, and explored attitudes about "risky" versus "safe" sex, before querying their own sexual behaviors. Typical prompts included what behaviors they had heard put individuals at risk for contracting HIV, whether and which sexual behavior(s) are relevant for discussions with providers, past experiences attempting to reduce HIV/STI transmission risk, and perceived situations in which avoiding risky sexual behavior could be difficult.

\section{Study Population and Recruitment}

We approached patients living with and without HIV at four US clinics within the Centers for AIDS Research Network of Integrated Clinical Systems (CNICS): Fenway Community Health (Boston, MA), 1917 Clinic (University of Alabama-Birmingham), Owen Clinic (University of California-San Diego), and Madison Clinic (Harborview Medical Center/University of WashingtonSeattle). Patients at these clinics complete PRO assessments on touch-screen tablets before visits. The PRO assessment included items that determined study eligibility. We recruited patients living with HIV (PLWH) in person before or after a clinic visit. Inclusion criteria were sexually active (anal and/or vaginal) with one or more partners in the past 12 months, women who had sex with women (WSW), and for others, condom use less than "all the time." We screened HIV-uninfected patients by phone for eligibility. We recruited a convenience sample with heterogeneous numbers of partners and risk levels. We sought to enroll a group with over half of subjects with $\geq$ two sex partners over the past year. We also sought to enroll a group with heterogeneous HIV/STI exposure risks, based on the model by Murphy et al. ${ }^{36}$ We defined those other than WSW who reported using condoms "never" and "some of the time" as a high-risk group, those who reported using condoms "most of the time" as a moderate risk group, and those using condoms "all of the time" as the lowest risk group.

For CE interviews, we sought robust representation of groups at highest risk for HIV/STI: transgender women, cisgender MSM and/or men who have sex with both men and women (MSMW), and cis-gender women who have sex with men exclusively or who have sex with men and women (WSM/WSMW). We attempted to match interviewer and participant sex to minimize patient discomfort; transgender patients chose the sex of their interviewer. We continued enrollment until reaching concept saturation, meaning that no new themes emerged from additional interview transcripts.

\section{Concept Elicitation Interview Coding, Matching to Legacy ltem Themes, and Development of New Content}

An independent transcription agency transcribed interviews. A multi-site qualitative research team excerpted potentially relevant interview content, using Dedoose software to apply item pool codes to excerpts. Two team members independently matched coded excerpts to legacy item themes; a third team member led discussions to reconcile discrepancies. We identified excerpts that did not match legacy item content as themes for potential new item development.

We wrote new items and adapted legacy items to reflect 3month recall periods, as recommended. ${ }^{37}$ We drafted a programmable algorithm using skip patterns based on single versus multiple partners, patient sex, partner gender identity, and patient/partner HIV serostatus (concordant vs. discordant). For example, MSM indicating sex exclusively with cis-gender males do not receive items regarding vaginal sex; PLWH reporting a single HIV-uninfected partner receive a partner pre-exposure prophylaxis (PrEP) use item; and so forth. We drafted items to approximate a sixth grade or lower English literacy level.

\section{Team and Clinician Review}

HIV care providers, co-investigators, and the qualitative team reviewed the drafted measure and assessed the frequency of SRB concepts from the qualitative data and the clinical relevance of each concept, defined as information likely to initiate/ change a provider's actions.

\section{Cognitive Interview Testing}

We tested the resulting items for comprehensibility, using the same recruitment criteria used for CE interviews. We showed patients items relevant to their sex, partner gender identity, and partner HIV status. Interviews were $\sim 45 \mathrm{~min}$ in length; participants received $\$ 15$ compensation. We calculated the number of patients that comprehended each item. We reviewed less-than-unanimously understood items for opportunities to clarify. We conducted interviews until reaching concept saturation.

\section{Development of SRBI}

We used all of these data elements to compose the final version of the SRBI. The instrument shows patients approximately 12 items, skip-patterned depending on behaviors (see Fig. 2).

\section{Comparison with the RAB}

We administered the SRBI via touch screen tablet to PLWH who completed the RAB the same day as part of routine clinic PRO collection and continued recruiting a convenience sample of patients living with and without HIV until achieving 


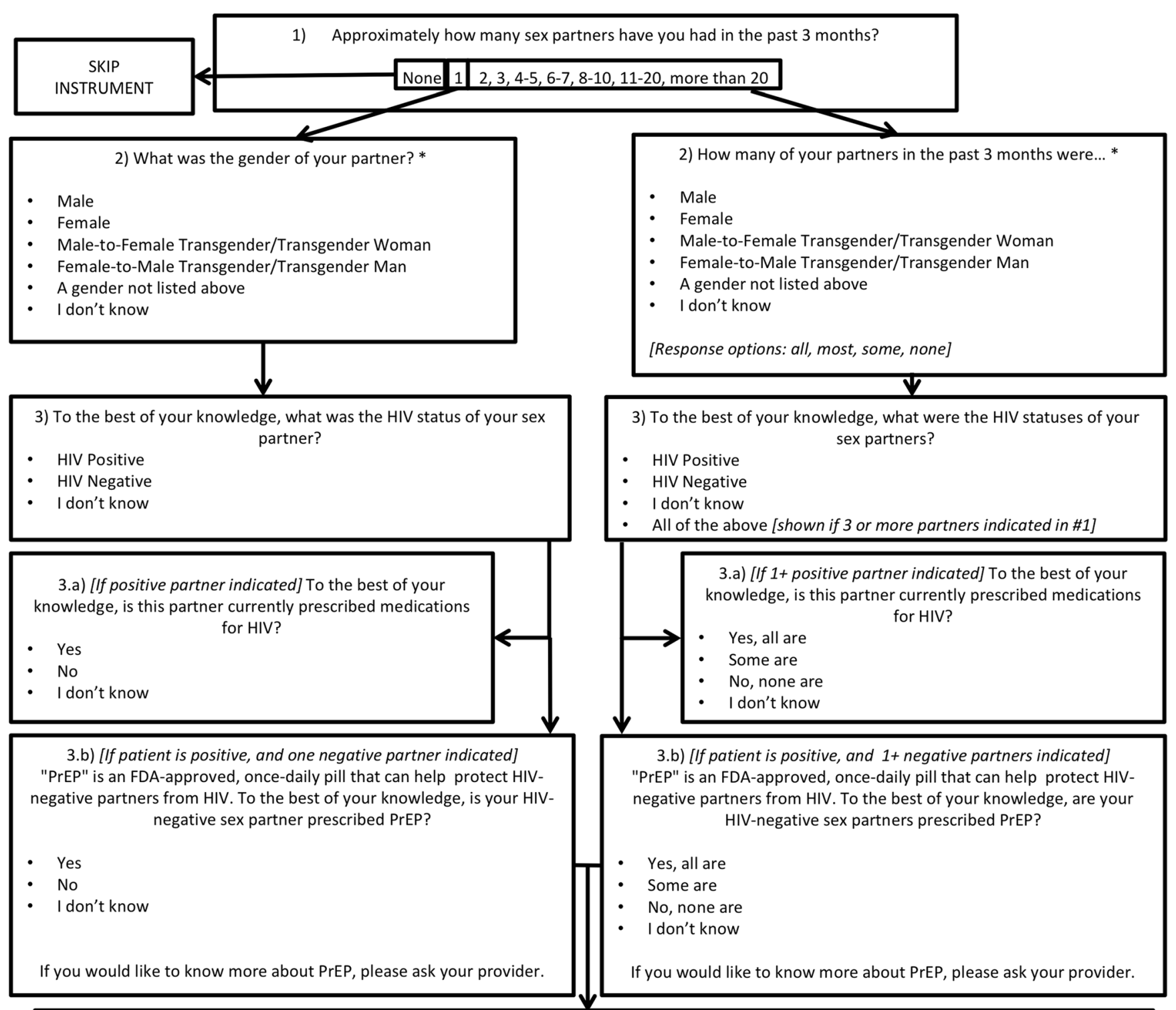

4) In the past 3 months, with your HIV [positive, negative, status unknown (separate screen shown for each status type)] partner/s, have you had....

- Oral sex without a condom or barrier protection? By oral sex, we mean when a mouth touches someone else's genitals

- Vaginal/frontal sex without a condom? By vaginal/frontal sex we mean a penis entering a vagina or front hole. ${ }^{* *}$ [Item shown for all but MSM; replaces word "condom" with "barrier protection" if WSW]

- Anal sex without a condom? By anal sex, we mean a penis entering an anus (butt) [not shown to WSW] [Response Options: Yes/No/l can't remember]

4.a) [If yes to anal sex without condoms AND are MSM or MTF, and who indicated partners that are male, MTF, 'a gender not listed above' or 'I don't know' on sex of partners item]

In the past 3 months, thinking about the times you had anal sex without condoms, please mark on the line how often you were the "bottom" (receiving partner).

[0\% of time-- $100 \%$ of time]

5) [if patient HIV-positive] In the past 3 months, have you been concerned that you may have been exposed to a sexually transmitted infection (STI) or re-exposed to HIV?
5) [if patient HIV-negative/HIV status not known] In the past 3 months, have you been concerned that you may have been exposed to HIV or another kind of sexually transmitted infection (STI)?

*: "What's this" button text reads: We realize that some people may have different ways of talking about gender. If you feel that none of these options apply, we would welcome your feedback.

**: "What's this" button above vaginal sex item; text reads: We realize that not everyone uses the same words to talk about their body parts. Please feel free to let your provider know what words you would like us to use. 
robust numbers of high-, medium-, and low-risk patients. Patients received $\$ 25$ for completing the additional measures.

\section{RESULTS}

\section{Concept Elicitation and Matching to Legacy Scale Themes}

Demographic and clinical characteristics of CE interview participants $(n=91)$ are shown in Table 1 .

We matched $\sim 400$ interview excerpts to legacy items, including the following concepts: number of sex partners; context of meeting sex partners (i.e., smartphone apps, websites); partner HIV/STI status; partner ART/PrEP status; partner HIV viral load; nature of partnership (i.e., long-term vs. anonymous); oral, anal, and vaginal sex behavior; condom use; sex addiction; sexual remorse; HIV/STI disclosure; sexual satisfaction; direction of anal sex; and concern regarding HIV/STI exposure. Concepts found in the interviews but not the item pool included partner serosorting, perceptions of partner fidelity, reasons for unsafe sex, concurrent sex partners, and group sex. The category "reasons for unsafe sex" had many matched and unmatched concepts, including having a low viral load, taking PrEP, low perceived HIV/STI risk, pregnancy goals, special occasions (i.e., anniversary), dislike/trouble using condoms, substance use, deference to partner's wishes, forced sex, loneliness, sadness/depression, and ambivalence. We drafted the most common concepts as potential items.

\section{Results of Team and Provider Meetings}

Providers $(n=7)$ found that several concepts lacked clinical relevance, including frequency of sex with barrier/condom protection, and direction of oral sex. Providers deemed overall number of partners and context of barrier protection (i.e., HIV status of partner) to be clinically relevant. We judged language querying "partner type," such as "casual," "primary," "steady," and "main," potentially confusing and more clearly elicited during direct patient-provider conversation. Similarly, we found a lengthy list of reasons for unsafe sex to be a poor fit for self-administration.

\section{Results of Cognitive Interview Testing}

Cognitive interview participants $(n=37)$ found the terms oral, vaginal, and anal sex confusing. We added clarifying statements such as "By oral sex, we mean when a mouth touches someone else's genitals." Several interview participants did not understand what was meant by the term "gender identity"; several were unfamiliar with PrEP. To address these concerns, we added clickable "what's this?" buttons that provide clarifying text. Transgender patients suggested addition of the term "front hole" alongside "vagina" to increase relevance to transgender women. Interview participants strongly favored the word "gender" to "sex."
Table 1 Demographics Across Activity Type

\begin{tabular}{|c|c|c|c|}
\hline & $\begin{array}{l}\text { Concept } \\
\text { elicitation }\end{array}$ & $\begin{array}{l}\text { Cognitive } \\
\text { interviews }\end{array}$ & $\overline{\text { Crosswalk }}$ \\
\hline Total & 91 & 37 & 422 \\
\hline \multicolumn{4}{|l|}{ HIV serostatus } \\
\hline $\mathrm{HIV}+$ & $67(74 \%)$ & $32(86 \%)$ & $375(89 \%)$ \\
\hline HIV- & $24(26 \%)$ & $5(14 \%)$ & $47(11 \%)$ \\
\hline \multicolumn{4}{|l|}{ Present sex } \\
\hline Male & $53(58 \%)$ & $22(59 \%)$ & $351(83 \%)$ \\
\hline Female & $28(31 \%)$ & $12(32 \%)$ & $67(16 \%)$ \\
\hline MTF transgender & $7(8 \%)$ & $3(8 \%)$ & $3(1 \%)$ \\
\hline FTM transgender & $3(3 \%)$ & $0(0 \%)$ & $1(<1 \%)$ \\
\hline \multicolumn{4}{|l|}{ Race } \\
\hline African-American & $31(34 \%)$ & $10(27 \%)$ & $110(26 \%)$ \\
\hline White & $50(55 \%)$ & $25(68 \%)$ & $281(67 \%)$ \\
\hline Asian-American, & $3(3 \%)$ & $2(5 \%)$ & $7(2 \%)$ \\
\hline \multicolumn{4}{|l|}{ Hawaiian, Pacific Islander } \\
\hline Native American & $0(0 \%)$ & $0(0 \%)$ & $2(<1 \%)$ \\
\hline $\begin{array}{l}\text { More than one race } \\
\text { or other race }\end{array}$ & $7(8 \%)$ & $0(0 \%)$ & $7(2 \%)$ \\
\hline Not reported & $0(0 \%)$ & $0(0 \%)$ & $15(4 \%)$ \\
\hline Latino/Hispanic, any race & $8(9 \%)$ & $5(14 \%)$ & $70(17 \%)$ \\
\hline \multicolumn{4}{|l|}{ Age } \\
\hline$<30$ & $24(26 \%)$ & $13(35 \%)$ & $68(16 \%)$ \\
\hline $30-39$ & $20(22 \%)$ & $10(27 \%)$ & $128(30 \%)$ \\
\hline $40-49$ & $24(26 \%)$ & $8(22 \%)$ & $125(30 \%)$ \\
\hline $50+$ & $23(25 \%)$ & $6(16 \%)$ & $101(24 \%)$ \\
\hline \multicolumn{4}{|c|}{ Sexual orientation, by behavior ${ }^{\mathrm{a}}$} \\
\hline $\mathrm{MSM}^{\mathrm{b}}$ & $44(48 \%)$ & $19(51 \%)$ & $297(70 \%)$ \\
\hline MSMW & $10(11 \%)$ & $5(14 \%)$ & $9(2 \%)$ \\
\hline MSW $^{\mathrm{b}}$ & $22(24 \%)$ & $8(22 \%)$ & $62(15 \%)$ \\
\hline WSM $^{\mathrm{c}}$ & $35(38 \%)$ & $15(41 \%)$ & $63(15 \%)$ \\
\hline WSMW & $9(10 \%)$ & $3(8 \%)$ & $1(<1 \%)$ \\
\hline $\mathrm{WSW}^{\mathrm{c}}$ & $9(10 \%)$ & $3(8 \%)$ & $8(2 \%)$ \\
\hline \multicolumn{4}{|l|}{ Sexual risk level ${ }^{\mathrm{d}}$} \\
\hline High & $26(29 \%)$ & $13(35 \%)$ & $278(66 \%)$ \\
\hline Moderate & $34(37 \%)$ & $19(51 \%)$ & $88(21 \%)$ \\
\hline Low & $31(34 \%)$ & $5(14 \%)$ & $56(13 \%)$ \\
\hline \multicolumn{4}{|l|}{ HIV+ only } \\
\hline \multicolumn{4}{|l|}{ Time since initial HIV diagnosis } \\
\hline $0-5$ years & $24(26 \%)$ & - & - \\
\hline $6-10$ years & $15(16 \%)$ & - & - \\
\hline$>10$ years & $28(31 \%)$ & - & - \\
\hline \multicolumn{4}{|l|}{ Route of transmission } \\
\hline MSM & $34(37 \%)$ & - & $238(63 \%)$ \\
\hline MSM/IV drug use & $3(3 \%)$ & - & $7(2 \%)$ \\
\hline IV drug use (non-MSM) & $4(4 \%)$ & _- & $40(11 \%)$ \\
\hline Heterosexual & $19(21 \%)$ & - & $78(21 \%)$ \\
\hline Other/unknown & $7(8 \%)$ & - & $12(3 \%)$ \\
\hline \multicolumn{4}{|l|}{ Most recent CD4 } \\
\hline $0-199$ & $3(3 \%)$ & _- & $28(7 \%)$ \\
\hline $200-349$ & $5(5 \%)$ & - & $46(12 \%)$ \\
\hline $350+$ & $59(65 \%)$ & - & $301(80 \%)$ \\
\hline
\end{tabular}

${ }^{a}$ Transgender patients represented by sex corresponding to current gender identity

${ }^{b}$ Includes men who have sex with men and women

cIncludes women who have sex with women and men

${ }^{d}$ High risk $=2+$ sex partners in the past 6 months and condom use "never "or "some of the time"

Moderate risk $=2+$ sex partners in past 6 months and condom use "most of the time"

Low risk= condom use "all of the time" with one or more partners MTF male to female (transgender), FTM female to male (transgender), MSM men who have sex with men, MSMW men who have sex with men and women, MSW men who have sex with women, WSM women who have sex with men, WSMW women who have sex with men and women, WSW women who have sex with women

\section{Resulting Final Measure and Crosswalk Testing}

The SRBI algorithm (Fig. 2) incorporates skip patterns and differential wording based on whether a respondent has one or multiple sex partners, sex-based partnership configuration (i.e., 
MSM, WSM), patient/partner HIV status, and endorsement of anal sex without condoms. Same-day administration of the RAB and SRBI $(n=422)$ revealed low levels of consistent condom use (10\%) among patients reporting anal or vaginal sex on the RAB. Per the SRBI, of patients reporting condom use "less than all the time" on the RAB, $22 \%$ did not know their partner/s HIV status; $16 \%$ reported not knowing whether one or more of their partners were prescribed ART/PrEP; 19\% reported having no partners prescribed ART/PrEP; $12 \%$ reported that some of their partners were prescribed ART/PrEP; and $38 \%$ reported that all partners were prescribed ART/PrEP.

\section{DISCUSSION}

Despite rising rates of STI in the USA ${ }^{1}$ and evidence of lessthan-adequate patient-provider discussions of SRB ${ }^{2-5,7-10,38}$ there are rays of hope. Evidence shows patient willingness to discuss SRB with providers ${ }^{3,39}$; that PROs reduce social desirability bias when compared to in-person interview in the area of sexual health ${ }^{40}$; and that discussions of SRB in care lead to additional screening and follow up ${ }^{41}$ as well as positive clinical outcomes. ${ }^{42}$ Further, as part of the movement toward patient-centered care practices, PROs have become more commonplace, ${ }^{43}$ with evidence of successful integration into routine care with results delivered to providers at the point of care. ${ }^{43,44}$ These combined factors highlight an opportunity to develop a targeted, brief, clinically relevant measure of SRB that helps initiate such discussions from a better-informed starting point. We designed the SRBI for this context. It uses terms for sex-related behaviors vetted by a diverse group of patients, which may facilitate conversations that could otherwise be uncomfortable. It focuses on SRB, avoiding distinctions that do not impact HIV/STI risk, while identifying specific behaviors - such as partner use of ART/PrEP - that were not addressed by legacy measures.

Concepts of SRB among patients were numerous, diverse, and at times specific to patients' sex, sexual orientation, and HIV status. This presented an opportunity to develop a skip pattern in the SRBI responsive to the modern context of sexual decision-making, to help illuminate patient decisions surrounding HIV/STI risk and prevention. For example, we found patients' decisions regarding whether to engage in condom-less sex to be heavily informed not only by knowledge or perception of one's own versus a partner's HIV status but also by use of ART, detectability of one's own/partner viral load, and, for MSM, positioning choice for anal intercourse. Such strategies have been noted elsewhere. ${ }^{45-48}$ Use of PrEP, known to be highly effective against HIV transmission, ${ }^{49-51}$ may also influence condom use. While condom use remains the gold standard beyond abstinence for HIV/STI protection, interviews suggested that assessment of condom use without accounting for these factors would be less informative of true risk behavior in the current ART era. Clearly, a patientprovider conversation about condom-less sex would differ in approach and content with, for example, a virally suppressed patient reporting one mutually monogamous, long-term, PrEP-adherent partner, than with virally unsuppressed patients not using condoms, or patients reporting condom-less sex with partners of unknown HIV status.

In comparing the RAB and SRBI, we found that simply measuring frequency of condom use in the absence of additional context provided by the SRBI failed to distinguish between high- and low-risk patients, limiting clinical usefulness of the RAB and measures exclusively focused on condom frequency. For example, a large proportion of patients reporting condom-less sex on the RAB (38\%) reported that all of their partners were prescribed either ART or PrEP on the SRBI, indicating some level of familiarity with sex partners and an effort to minimize HIV transmission risk. This circumstance contrasts sharply with that of the $22 \%$ of patients that did not know their partner/s HIV status. The SRBI stratifies patterns of behavior based on our overarching definition of SRB, relating specifically to risk of HIV/STI transmission.

In selecting items for the final measure, we balanced several factors: degree of clinical relevance, the need for richer contextualization of risk behavior, imagined patient tolerability of items, and the need for brevity. To ensure clinical relevance, we crafted the measure to target current SRB pertinent from a HIV/STI prevention standpoint, excluding assessment of "protected" sex practices and lifetime items frequently found in other SRB measures. ${ }^{32,35,52}$ Instead, we query whether or not the patient had sex without condoms or barrier protection, in the context of what the patient perceives about their own and partner HIV/STI, ART/PrEP, and viral load status. We also considered the clinical relevance of identifying partnership type, as item pool language referencing it was vague, confusing, and subject to misinterpretation even when defined. Examples of troublesome language are binaries such as "primary/ secondary," and terms such as "non-primary," casual, steady, and/or main to describe partners. Few patients interviewed used such language, instead using terms such as "friend," "husband," "girlfriend," "someone I hook up with," or "f-k buddy." Given that none of these terms reliably indicate level of sexual exclusivity, or even familiarity, we deemed partnership type to be both less clinically relevant and more effectively elicited in the context of a patient-provider conversation if needed.

In discussions of patient tolerability of items, the issue arose of how much supporting context warrants inclusion in the measure, and whether that context is best elicited by a PRO measure, versus a face-to-face conversation. While reasons for unsafe sex was considered potentially clinically relevant, the patient burden of reviewing and selecting from a lengthy list of wildly diverse reasons ranging from positive emotional states (i.e., "anniversary") to sexual violence was believed to outweigh any benefit. We concluded that the most clinically relevant "reasons," namely depression, substance use, and sexual violence, were better assessed by other PRO measures, such as the PHQ-9 for depression; others could be more effectively elicited from face-to-face conversations. In this 
spirit, we visualized a measure that facilitates, rather than replaces, patient-provider discussion of SRB.

The use of PROs to facilitate SRB discussions bears particular importance for identifying and treating patients that engage in same-sex sexual behavior. Lesbian, gay, bisexual, and transgender patients experience significant health disparities, including increased suicide attempts among youth, HIV/STI risk, and substance use. ${ }^{53}$ Providers may often be the only ones with whom patients can disclose and discuss sexual behavior, sexuality, and/or gender identity without negative consequence. ${ }^{53}$ Hence, we strongly recommend collection of patient-reported gender identity and sexual orientation to complement assessment of SRB. For all patient populations, same-day, patientreported SRB measurement may reduce the potential awkwardness of bringing the topic up "cold" or seemingly at random in the context of a time-constrained appointment, generating the possibility of a more honest, well-informed, and targeted discussion. The SRBI in particular offers a clinically relevant, comprehensive yet brief means of assessing SRB, helping providers to distinguish true levels of patient HIV/STI risk by providing fuller context surrounding condom-less sex, and to determine when to test for HIV/STIs. Further validation work should assess the SRBI's predictive value of incident HIV/STI.

\section{LIMITATIONS}

This study has a few limitations. First, despite the many concepts elicited from CE interviews, we note that the private nature of SRB could have limited patient discussion. Second, while our patient sample included WSMW, it included few WSW who did not also have sex with men, due to low numbers in our clinic populations. Because of this, the measure may be less relevant or generalizable to lesbian-identified women/WSW who do not have sex with men. Third, the SRBI focuses on sexual risk behavior, and not contextual factors (e.g., substance use, depression, etc.). Those seeking to understand contexts underlying SRB would need to assess these with other instruments. Fourth, we developed the SRBI specifically for electronic administration using skip pattern logic and have no information regarding whether this approach could work as a paper-based assessment. Fifth, we note the need to assess patient satisfaction with the SRBI. Finally, we caution that patient use of ART/PrEP does not reduce nonHIV STI risk; use of the SRBI is meant to inform, not replace, discussion of both HIV and non-HIV STI transmission risk.

\section{STRENGTHS}

We recruited a diverse patient population with respect to demographic characteristics, sexual orientation, gender identity, sex of sex partners, and risk levels, which we believe enriched development of the SRBI. In addition, this work drew on the expertise of researchers, many of them HIV care providers.

\section{CONCLUSION}

Concept elicitation of sexual risk among HIV-infected and uninfected patients yielded rich, diverse content and underscored the need for a skip-patterned measure of SRB relevant across sex, sexual orientation, gender identity, and partnership configurations that incorporates factors influencing decisions whether or not to use barrier protection in the current era of ART and PrEP. Provider input and patient cognitive interviews furnished development of the SRBI, a brief, clinically relevant, comprehensive, well-tolerated SRB measure that may promote more meaningful discussion of sexual risk in the context of routine clinical care.

Acknowledgments: We thank our patients for their time, candor, and insights. This research was funded by a cooperative agreement awarded to the University of Washington (Principal Investigators: $D$ Patrick, $H$ Crane, $P$ Crane) from the National Institute of Allergy and Infectious Diseases (NIAID) and National Institute of Arthritis and Musculoskeletal and Skin Diseases (NIAMS) (Grant No. UO1 AR057954). Support was also provided by the National Institute of Allergy and Infectious Diseases (NIAID) University of Washington Center for AIDS Research (Grant No. P3O AIO27757) and CNICS (R24AIO67039) and National Institute of Alcohol Abuse and Alcoholism (NIAAA) (ARCH Grants UO1 AA020802, UO1 AA020793, and U24AA020801).

Corresponding Author: Rob J. Fredericksen, PhD; Center for AIDS Research University of Washington, Seattle, WA, USA (e-mail: rfrederi@uw.edu).

\section{Compliance with Ethical Standards:}

Conflict of Interest: The authors declare that they do not have a conflict of interest.

\section{REFERENCES}

1. Reported cases of STD's on the rise in the U.S. 2015. March 2, 2018. Available from: http://www.cdc.gov/nchhstp/newsroom/2015/std-surveillance-report-press-release.html.

2. Wimberly YH, Hogben M, Moore-Ruffin J, Moore SE, Fry-Johnson Y. Sexual history-taking among primary care physicians. J Natl Med Assoc 2006;98(12):1924-9.

3. Talking with patients about sexuality and sexual health. Clinical fact sheets [Internet]. 2010; (March 2, 2018). Available from: http://www. arhp.org/publications-and-resources/clinical-fact-sheets/shf-talking.

4. Glaude-Hosch JA, Smith ML, Heckman TG, Miles TP, Olubajo BA, Ory MG. Sexual Behaviors, Healthcare Interactions, and HIV-Related Perceptions Among Adults Age 60 Years and Older: An Investigation by Race/Ethnicity. Curr HIV Res 2015;13(5):359-68.

5. Savasta AM. HIV: associated transmission risks in older adults-an integrative review of the literature. $J$ Assoc Nurses AIDS Care 2004;15(1):50-9.

6. Wolitski RJ, Fenton KA. Sexual health, HIV, and sexually transmitted infections among gay, bisexual, and other men who have sex with men in the United States. AIDS Behav 2011;15 Suppl 1:S9-17.

7. Gardner LI, Metsch L, Strathdee SA, del Rio C, Mahoney P, Holmberg SD, et al. Frequency of discussing HIV prevention and care topics with patients with HIV: influence of physician gender, race/ethnicity, and practice characteristics. Gender Medicine 2008;5(3):259-69.

8. Marquez C, Mitchell SJ, Hare CB, John M, Klausner JD. Methamphetamine use, sexual activity, patient-provider communication, and medication adherence among HIV-infected patients in care, San Francisco 2004-2006. AIDS Care 2009;21(5):575-82.

9. Laws MB, Bradshaw YS, Safren SA, Beach MC, Lee Y, Rogers W, et al. Discussion of sexual risk behavior in HIV care is infrequent and appears ineffectual: a mixed methods study. AIDS Behav 2011;15(4):812-22. 
10. Drainoni ML, Dekker D, Lee-Hood E, Boehmer U, Relf M. HIV medical care provider practices for reducing high-risk sexual behavior: results of a qualitative study. AIDS Patient Care STDs 2009;23(5):347-56.

11. Morin SF, Koester KA, Steward WT, Maiorana A, McLaughlin M, Myers JJ, et al. Missed opportunities: prevention with HIV-infected patients in clinical care settings. J Acquir Immune Defic Syndr 2004;36(4):960-6

12. Burd ID, Nevadunsky N, Bachmann G. Impact of physician gender on sexual history taking in a multispecialty practice. J Sex Med 2006;3(2):194-200.

13. Politi MC, Clark MA, Armstrong G, McGarry KA, Sciamanna CN. Patient-provider communication about sexual health among unmarried middle-aged and older women. J Gen Intern Med 2009;24(4):511-6.

14. Hayes V, Blondeau W, Bing-You RG. Assessment of Medical Student and Resident/Fellow Knowledge, Comfort, and Training With Sexual History Taking in LGBTQ Patients. Fam Med 2015;47(5):383-7.

15. Lurie N, Margolis K, McGovern PG, Mink P. Physician self-report of comfort and skill in providing preventive care to patients of the opposite sex. Arch Fam Med 1998;7(2):134-7.

16. Tao G, Irwin KL, Kassler WJ. Missed opportunities to assess sexually transmitted diseases in U.S. adults during routine medical checkups. Am J Prev Med 2000;18(2):109-14.

17. Morrison-Beedy D, Carey MP, Tu X. Accuracy of audio computerassisted self-interviewing (ACASI) and self-administered questionnaires for the assessment of sexual behavior. AIDS Behav 2006;10(5):541-52.

18. Dolezal C, Marhefka SL, Santamaria EK, Leu CS, Brackis-Cott E, Mellins CA. A comparison of audio computer-assisted self-interviews to face-to-face interviews of sexual behavior among perinatally HIV-exposed youth. Arch Sex Behav 2012;41(2):401-10.

19. Macalino GE, Celentano DD, Latkin C, Strathdee SA, Vlahov D. Risk behaviors by audio computer-assisted self-interviews among HIVseropositive and HIV-seronegative injection drug users. AIDS Educ Prev 2002; 14(5):367-78.

20. Schroder KE, Carey MP, Vanable PA. Methodological challenges in research on sexual risk behavior: II. Accuracy of self-reports. Ann Behav Med 2003;26(2):104-23.

21. Sharma P, Dunn RL, Wei JT, Montie JE, Gilbert SM. Evaluation of point-of-care PRO assessment in clinic settings: integration, parallelforms reliability, and patient acceptability of electronic QOL measures during clinic visits. Qual Life Res 2016;25(3):575-83.

22. Stover A, Irwin DE, Chen RC, Chera BS, Mayer DK, Muss HB, et al. Integrating Patient-Reported Outcome Measures into Routine Cancer Care: Cancer Patients' and Clinicians' Perceptions of Acceptability and Value. EGEMS (Wash DC) 2015;3(1):1169.

23. Jones J, Stephenson R, Smith DK, Toledo L, La Pointe A, Taussig J, et al. Acceptability and willingness among men who have sex with men (MSM) to use a tablet-based HIV risk assessment in a clinical setting. Springerplus 2014;3:708.

24. Fredericksen RJ, Tufano J, Ralston J, McReynolds J, Stewart M, Lober WB, et al. Provider perceptions of the value of same-day, electronic patientreported measures for use in clinical HIV care. AIDS Care 2016 1-6.

25. Crane HM, Crane PK, Tufano JT, Ralston JD, Wilson IB, Brown TD, et al. HIV Provider Documentation and Actions Following Patient Reports of At-risk Behaviors and Conditions When Identified by a Web-Based Point-of-Care Assessment. AIDS Behav 2017;21(11):3111-21.

26. Metraux S, Metzger DS, Culhane DP. Homelessness and HIV risk behaviors among injection drug users. J Urban Health 2004;81(4):61829.

27. Rosenberg SD, Trumbetta SL, Mueser KT, Goodman LA, Osher FC, Vidaver RM, et al. Determinants of risk behavior for human immunodeficiency virus/acquired immunodeficiency syndrome in people with severe mental illness. Compr Psychiatry 2001;42(4):263-71.

28. Noar SM, Cole C, Carlyle K. Condom use measurement in 56 studies of sexual risk behavior: review and recommendations. Arch Sex Behav 2006;35(3):327-45.

29. George W, Zawacki T, Simoni J, Stephens K, Lindgren K. Assessment of sexually risky behaviors. Assessment of addictive behaviors. 2nd ed: Guilford Press; 2007.

30. Fenton KA, Johnson AM, McManus S, Erens B. Measuring sexual behaviour: methodological challenges in survey research. Sex Transm Infect 2001;77(2):84-92.

31. Sheeran P, Abraham C. Measurement of condom use in 72 studies of HIV-preventive behaviour: a critical review. Patient Educ Couns 1994;24(3):199-216.

32. Turchik JA, Garske JP. Measurement of sexual risk taking among college students. Arch Sex Behav 2009;38(6):936-48.
33. Cella D, Yount S, Rothrock N, Gershon R, Cook K, Reeve B, et al. The Patient-Reported Outcomes Measurement Information System (PROMIS): progress of an NIH Roadmap cooperative group during its first two years. Med Care 2007;45(5 Suppl 1):S3-S11.

34. DeWalt DA, Rothrock N, Yount S, Stone AA, Group PC. Evaluation of item candidates: the PROMIS qualitative item review. Med Care 2007;45(5 Suppl 1):S12-21.

35. Metzger DS, Nalvalline HA, Woody GE. Assessment of substance abuse: HIV risk assessment battery. In: Carson-Dewitt, editor. Encyclopedia of Drugs, Alcohol, and Addictive Behavior. Farmington Hills, MI: Macmillian Reference USA; 2001.

36. Murphy DA, Brecht ML, Herbeck DM, Huang D. Trajectories of HIV risk behavior from age 15 to 25 in the national longitudinal survey of youth sample. Journal of Youth and Adolescence 2009;38(9):1226-39.

37. Kauth MR, St Lawrence JS, Kelly JA. Reliability of retrospective assessments of sexual HIV risk behavior: a comparison of biweekly, three-month, and twelve-month self-reports. AIDS Educ Prev 1991;3(3):207-14.

38. Fredericksen R, Crane PK, Feldman BJ, Tufano J, Harrington RD, Dhanireddy S, et al. Impact of same-day pre-visit electronic patientreported outcome (PRO) collection on provider assessment of sexual risk and other behaviors of HIV-infected patients in routine clinical care. American Public Health Association 139th Annual Meeting; Oct 29-Nov 2, 2011; Washington, D.C.2011.

39. Fredericksen RJ, Edwards TC, Merlin JS, Gibbons LE, Rao D, Batey DS, et al. Patient and provider priorities for self-reported domains of HIV clinical care. AIDS Care 2015;27(10):1255-64.

40. Fairley CK, Sze JK, Vodstrcil LA, Chen MY. Computer-assisted self interviewing in sexual health clinics. Sex Transm Dis 2010;37(11):665-8.

41. Meanley S, Gale A, Harmell C, Jadwin-Cakmak L, Pingel E, Bauermeister JA. The role of provider interactions on comprehensive sexual healthcare among young men who have sex with men. AIDS Educ Prev 2015;27(1):15-26.

42. Fisher JD, Fisher WA, Cornman DH, Amico RK, Bryan A, Friedland GH. Clinician-delivered intervention during routine clinical care reduces unprotected sexual behavior among HIV-infected patients. J Acquir Immune Defic Syndr 2006;41(1):44-52.

43. Jensen RE, Rothrock NE, DeWitt EM, Spiegel B, Tucker CA, Crane HM, et al. The role of technical advances in the adoption and integration of patient-reported outcomes in clinical care. Med Care 2015;53(2):153-9.

44. Fredericksen R, Crane P, Tufano J, Ralston J, Schmidt S, Brown T, et al. Integrating a web-based patient assessment into primary care for HIV-infected adults. J AIDS HIV Res 2012;4(1).

45. Golub SA, Tomassilli JC, Pantalone DW, Brennan M, Karpiak SE, Parsons JT. Prevalence and correlates of sexual behavior and risk management among HIV-positive adults over 50. Sex Transm Dis 2010;37(10):615-20.

46. Parsons JT, Schrimshaw EW, Wolitski RJ, Halkitis PN, Purcell DW, Hoff CC, et al. Sexual harm reduction practices of HIV-seropositive gay and bisexual men: serosorting, strategic positioning, and withdrawal before ejaculation. AIDS 2005; 19 Suppl 1:S13-25.

47. Grov C, Rendina HJ, Moody RL, Ventuneac A, Parsons JT. HIV Serosorting, Status Disclosure, and Strategic Positioning Among Highly Sexually Active Gay and Bisexual Men. AIDS Patient Care STDs 2015;29(10):559-68.

48. Bruce D, Harper GW, Suleta $\mathbf{K}$, Adolescent Medicine Trials Network for HIVAI. Sexual risk behavior and risk reduction beliefs among HIV-positive young men who have sex with men. AIDS Behav 2013;17(4):1515-23.

49. Daar ES, Corado K. Condomless Sex With Virologically Suppressed HIVInfected Individuals: How Safe Is It? JAMA 2016;316(2):149-51.

50. Vernazza P, Hirschel B, Bernasconi E, Flepp M. Les personnes séropositives ne souffrant d'aucune autre MST et suivant un traitement antirétroviral efficace ne transmettent pas le VIH par voie sexuelle. Bulletin des médecins suisses 2008;89(5):165-9.

51. Loutfy MR, Wu W, Letchumanan M, Bondy L, Antoniou T, Margolese $\mathbf{S}$, et al. Systematic review of HIV transmission between heterosexual serodiscordant couples where the HIV-positive partner is fully suppressed on antiretroviral therapy. PLoS One 2013. https://doi.org/10.1371/ journal.pone.0055747

52. Donenberg GR, Emerson E, Bryant FB, Wilson H, Weber-Shifrin E. Understanding AIDS-risk behavior among adolescents in psychiatric care: links to psychopathology and peer relationships. J Am Acad Child Adolesc Psychiatry 2001;40(6):642-53.

53. Healthy people 2020: Lesbian, gay, bisexual, and transgender health. Office of Disease Prevention and Health Promotion. 